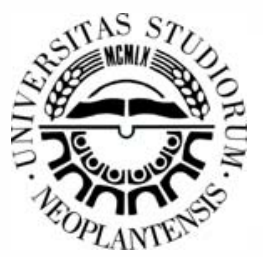

\title{
TiAlN tribological coatings prepared in industrial deposition system with different rotations
}

\author{
Aleksandar Miletič, ${ }^{a *}$ Peter Panjan, ${ }^{b}$ Miha Čekada, ${ }^{b}$ Pal Terek, ${ }^{a}$ Lazar Kovačević,,${ }^{a}$ Branko \\ ${\breve{S} k o r i c^{a}}^{a}$ \\ ${ }^{a}$ University of Novi Sad, Faculty of Technical Sciences, Novi Sad, Serbia \\ ${ }^{b}$ Jozef Stefan Institute, Department of Thin Films and Surfaces, Jamova Cesta 39, 1000 Ljubljana, Slovenia
}

\begin{abstract}
Efficiency and lifetime of manufacturing tools and mechanical components may be successfully improved by application of thin ceramic coatings. When it comes to tools for machining of hard materials such as machining of hardened steel, TiAlN is one of the most usually applied coatings. This material is of high hardness, high oxidation resistance and high temperature stability. In this research, surface morphology, mechanical and tribological properties of TiAlN coatings prepared in industrial deposition unit were studied. Three different coatings were prepared by selecting different rotational types in a magnetron sputtering deposition chamber. Surface morphology was characterized by stylus profilometry and atomic force microscopy, mechanical properties by nanoindentation technique and Rockwell indentation test, while pin-on-plate test was used to study tribological behavior. It was found that coatings prepared by higher number of rotations are smoother, harder, and more resistant to cracking and wear. These differences are attributed to differences in coating microstructure which refines with increased number of rotations.
\end{abstract}

Key words: Thin ceramic coating; TiAlN; magnetron sputtering; mechanical properties, friction, wear.

\section{INIRODUCTION}

In order to provide high productivity at low costs, along with meeting the harsh ecology standards, machining tools have to be protected with hard ceramic coatings. Approximately $90 \%$ of all machining tools are protected by some type of ceramic coating. Mostly nitrides such as TiAlN and CrAlN, oxides such is $\mathrm{Al}_{2} \mathrm{O}_{3}$, and carbides such as TiCN are applied on tool surfaces.

TiAlN coatings are widely applied due to their high hardness (around $32 \mathrm{GPa}$ ), high oxidation resistance (up to $800{ }^{\circ} \mathrm{C}$ ), and high temperature stability (up to $900^{\circ} \mathrm{C}$ ) [1]-[6]. They are especially suitable for machining of hard materials, such as hardened steel, even without lubrication. Thin ceramic coatings are applied on tools in special deposition chambers. When physical vapor deposition (PVD) techniques are used, tools have to be mounted on special fixation systems which enable complex rotation which is necessary for achieving the uniform deposition on all tool surfaces. Such a fixation system of the industrial deposition unit used in this research is presented in Fig. 1.
This system enables three different rotation types named 1fold, 2-fold, and 3-fold rotation. In 1-fold rotation, samples rotate around the first rotational axis, which is the axis of symmetry of the whole turntable. In 2-fold rotation, samples rotate around the first and the second rotational axis. The second rotational axis is the axis of symmetry of substrate towers. Finally, in 3-fold rotation, samples rotate around three axes, the first, the second, and the third, where the third rotational axis is axis of symmetry of tool holders. Although during coating deposition different parameters such as partial pressure of active and reactive gases, power on targets, bias voltage, and others are same for all samples, yet the deposition conditions are not same for the samples mounted in different rotation types. Namely, there are differences in the trajectory, and orientation of samples relative to targets [7], [8]. In 1-fold rotation samples move along circular trajectory, in 2-fold along helical trajectory, while in 3-fold rotation the trajectory is a double helix. Orientation of samples toward targets does not change during deposition in 1-fold rotation, while this is not true for 2 -fold and 3 -fold rotations. This means that samples

* Corresponding author's.e-mail: aleksandarvmiletic@gmail.com 
mounted in different rotations spend different time in plasma, which is the longest for the 1-fold rotation, and that as a consequence deposition rate is different for different rotations. In reactive physical vapor deposition, changes in deposition rate might lead to changes in chemical composition and coating microstructure [8].

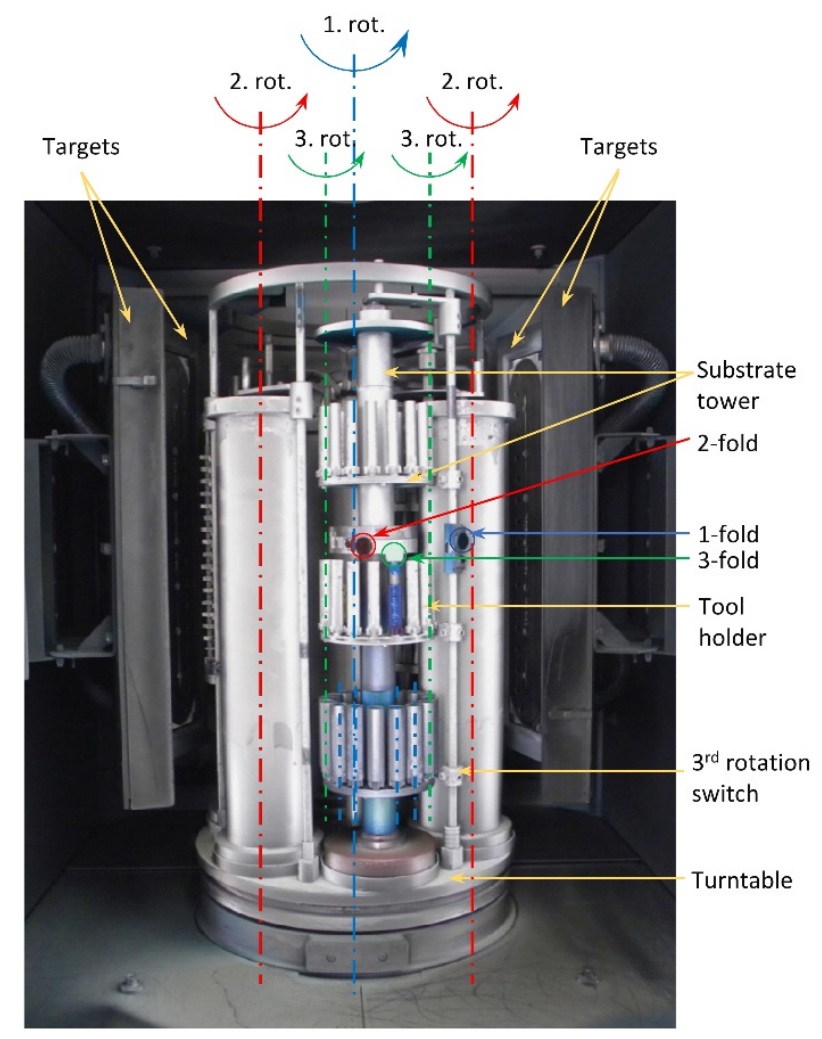

Fig. 1 Interior of CemeCon CC800/9 PVD magnetron sputtering deposition unit.

The main goal of this research is to study the change in surface topography, mechanical properties, and tribological behavior of TiAlN coatings with the change in the selected rotation type. For that purpose, three different TiAlN coatings were prepared by mounting the samples in different rotations, as shown in Fig. 1, within the same batch.

\section{EXPERIMENTAL DETAILS}

\subsection{Preparation of coatings}

Three TiAlN coatings were prepared in an industrial magnetron sputtering unit (CC 800/9). The unit is equipped with four DC powered unbalanced magnetron sources and planetary rotational turntable, as shown in Fig. 1. During deposition only two sources were used, coatings were deposited from TiAl targets. The turntable enables continuous 1-fold and 2-fold rotations, with a gear ratio of $100: 37$. In the 3 -fold rotation, rotation around third axis is not continuous, it is achieved by a switch which rotates the tool holder for around $160^{\circ}$. More details about turntable can be found in [9]. Cold work tool steel EN $\mathrm{X} 160 \mathrm{CrMoV} 121$ (AISI D2) was used as a substrate material. Prior to deposition, steel samples were ground, polished by a $3 \mu \mathrm{m}$ diamond paste, ultrasonically cleaned and dried in hot air. During the deposition following parameters were used: working pressure $0.66 \mathrm{~Pa}$, power on targets $9.5 \mathrm{~kW}$, bias $-90 \mathrm{~V}$, nitrogen flow $100 \mathrm{ml} / \mathrm{min}$, rotation rate $1 \mathrm{rev} / \mathrm{min}$. Vacuum chamber was heated to $450^{\circ}$ prior to coating deposition.

\section{Characterization of coatings}

Surface topography of coated samples was analyzed by $3 \mathrm{D}$ stylus profilometry. For achieving the higher magnification of surface features, atomic force microscopy (AFM) was utilized. For that purpose, Veeco di CP-II was used in contact mode, with scanned area of $90 \times 90 \mu \mathrm{m}$. Cracking resistance and coating adhesion were assessed by a standard HRC test (VDI 3198) [10]. In this test, a Rockwell C diamond prism is indented into a coated sample with a load of $150 \mathrm{~kg}$. Coating quality is then determined by observing the formed indent, number of cracks and areas of delaminated zones around the indent. Nanoindentation technique was utilized to acquire mechanical properties. For that purpose, Fischerscope $\mathrm{H} 100 \mathrm{C}$ tester and Vickers diamond indenter were used. Oliver-Pharr method [11] was applied to calculate hardness (H) and modulus of elasticity (E). Tribological properties were evaluated by a ball-on-plate methodology. Tribological tests were run in dry air, at room temperature. Alumina ball with diameter of $6 \mathrm{~mm}$ was used as a counterbody. Linear velocity was kept at $5 \mathrm{~cm} / \mathrm{s}$, normal load at 5 $\mathrm{N}$, stroke length at $5 \mathrm{~mm}$, and number of cycles at 2000 for all coatings. Confocal optical microscopy was used to observe samples after tribological test. Generated wear tracks were measured by 2D stylus profilometry. Energy dispersive X-ray spectroscopy (EDS) was used for elemental analysis of wear tracks, it was conducted inside scanning electron microscope JEOL JSM-7600F.

\section{RESULTS AND DISCUSSION}

Three-dimensional images of surface topography acquired by stylus profilometry and atomic force microscopy are presented in Fig. 2. Beside each image, surface roughness parameters are provided. Growth defects, which are typical for PVD coatings, are dominating surface features in images obtained by $3 \mathrm{D}$ stylus profilometry. It may be seen that size of these defects reduces with increased number of rotations. Accordingly, both average surface roughness $\left(\mathrm{S}_{\mathrm{a}}\right)$ and root mean square roughness $\left(\mathrm{S}_{\mathrm{q}}\right)$ decrease with increased number of rotations. Smaller surface features may be seen in AFM images. Protruding features in these images present upper parts of individual columns, which usually constitute microstructure of PVD grown coatings. These images reveal that size of the columns reduces with increased number of rotations, i.e. that coating microstructure becomes finer. Consequently, coatings prepared with 2-fold and 3-fold rotations are of much lower surface roughness $\left(\mathrm{S}_{\mathrm{a} 2 \text {-fold }}=18 \mathrm{~nm}, \mathrm{~S}_{\mathrm{a} 3 \text {-fold }}=14 \mathrm{~nm}\right)$ than coating prepared with 1 -fold rotation $\left(S_{a}=37 \mathrm{~nm}\right)$. 

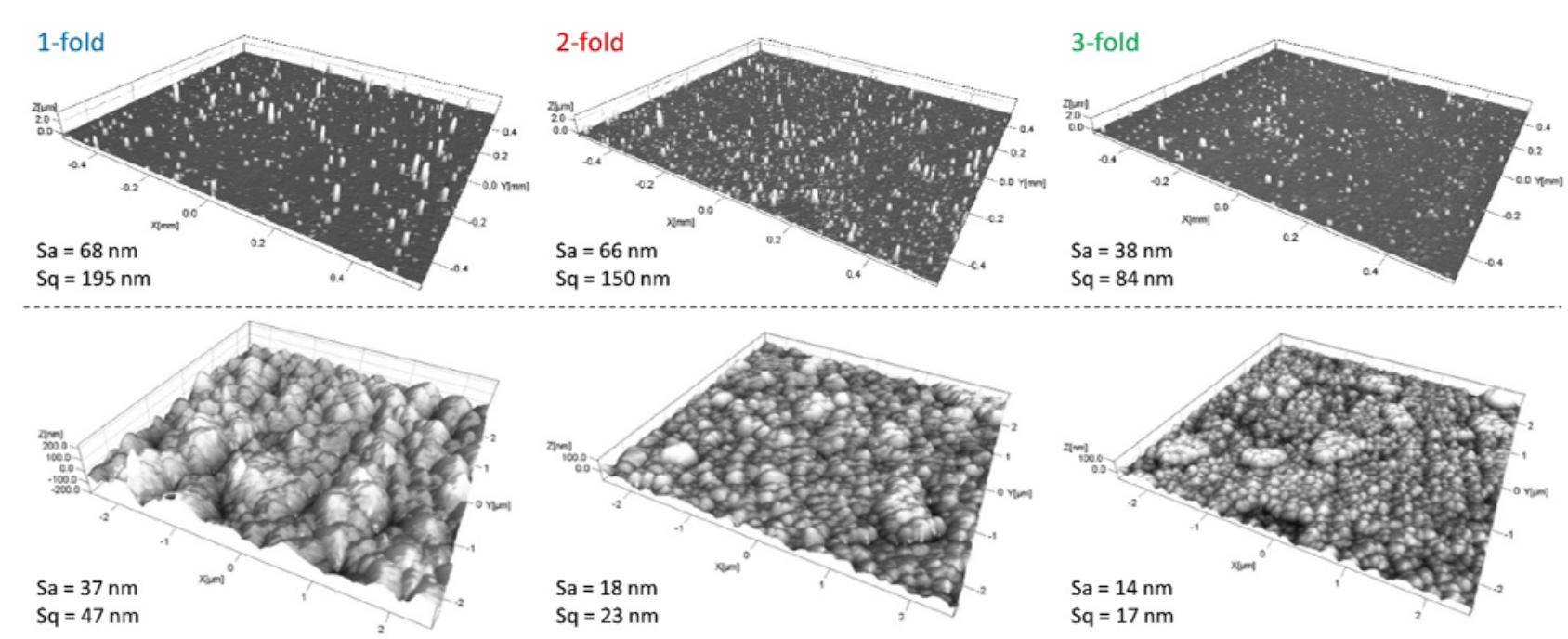

Fig. 2 Surface topography of TiAIN coatings deposited with different rotations obtained by stylus profilometry (upper row) and atomic force microscopy (lower row).

Indents generated in TiAlN coatings by Rockwell $\mathrm{C}$ prism are presented in Fig. 3.
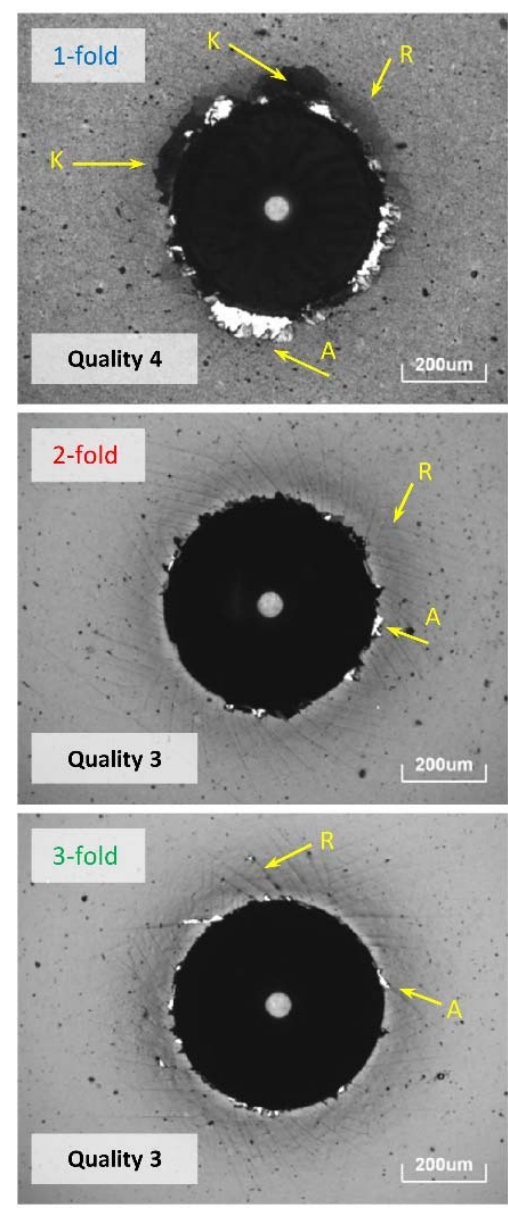

Fig. 3 HRC indents. Designations " $A$ ", " $K$ ", and "R" indicate adhesive detachment, cohesive detachment, and radial cracks, respectively.

High number of radial cracks was observed around each indent, while there were no circumferential cracks. Large areas of adhesive detachment, as well as areas of cohesive coating spallation may be seen around indent of TiAlN coating prepared by 1 -fold rotation. On the other side, only smaller zones of complete coating detachment are seen around indents in 2-fold and 3-fold coatings. This implies that both cohesive strength (cracking resistance), and adhesive strength between coating and substrate are higher for coatings prepared with higher number of rotations.

Thickness and mechanical properties of three coatings are presented in Table 1. Coating thickness decreases with increasing the number of rotations, which is related to change in the deposition rate which is highest for coatings prepared with 1 -fold rotation. The deposition rate is the highest for the samples which spend more time in dense plasma [9].

Table 1 - Thickness (d), hardness $(H)$, modulus of elasticity (E), elastic recovery $\left(W_{e}\right)$ and $H^{3} / E^{\star 2}$ ratio.

\begin{tabular}{lccc}
\hline Property & 1 - fold & 2 -fold & 3 - fold \\
\hline $\mathrm{d}(\mu \mathrm{m})$ & 6.9 & 3.4 & 2.1 \\
$\mathrm{H}(\mathrm{GPa})$ & $19 \pm 6$ & $24 \pm 2$ & $27 \pm 3$ \\
$\mathrm{E}(\mathrm{GPa})$ & $352 \pm 67$ & $345 \pm 22$ & $337 \pm 33$ \\
$\mathrm{We}(\%)$ & $44 \pm 4$ & $52 \pm 2$ & $56 \pm 1$ \\
$\mathrm{H}^{3} / \mathrm{E}^{* 2}(\mathrm{GPa})$ & 0.05 & 0.1 & 0.15 \\
\hline
\end{tabular}

Table 1 shows that coating hardness, elastic recovery, as well as ratio of hardness and modulus of elasticity $\mathrm{H}^{3} / \mathrm{E}^{* 2}$ are lowest for 1-fold coating, and highest for 3-fold coating. When it comes to wear resistance, in past the greatest attention was given to hardness. Nowadays, both elastic recovery and $\mathrm{H}^{3} / \mathrm{E}^{* 2}$ ratio, which is related to coating cracking resistance, are also recognized as important parameters for tribological behavior. Improvement in mechanical properties is directly related to the improvement in microstructure which becomes finer when number of rotations is increased. 


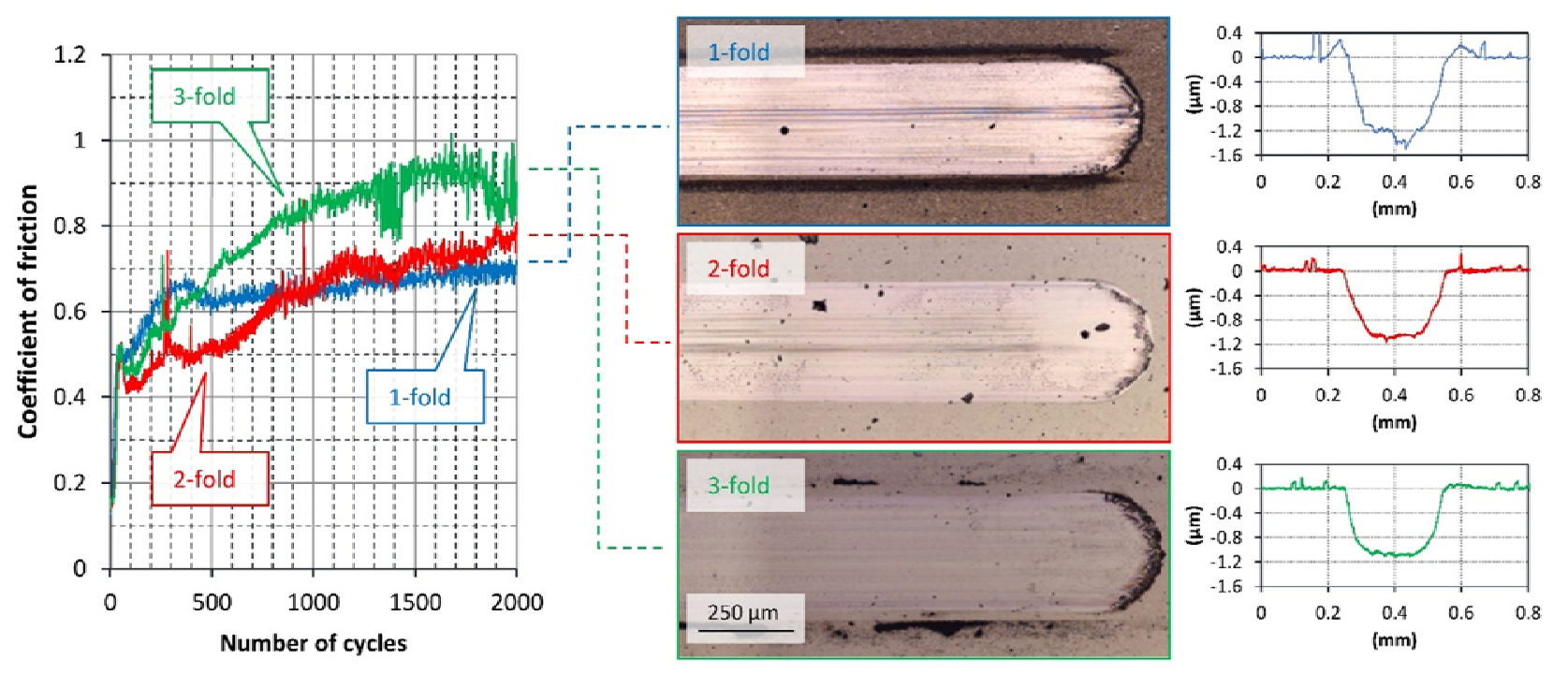

Fig. 4 Evolution of friction coefficient (left), optical images of wear tracks (middle) and wear track profiles (right).

Results of tribological test are presented in Fig. 4. Friction curves of all three coatings exhibit two stages, running-in, and transitional stage, while steady-stage was reached only for the coating prepared with three rotations. In the first stage, friction coefficient increases quickly to approximately 0.5 for all coatings. Transitional stage begins after around 50 cycles. First coefficient of friction decreases and after short number of cycles it increases relatively steeply without large sudden variations.

Considering that steady-state was not reached for all three coatings, average values of friction coefficient were calculated for cycles from 1000 to 2000 , and are presented in Table 2. It may be seen that friction coefficient is between 0.7 and 0.9 , which are values typical for TiAlN coating in contact with alumina [10], [11].

Table 2- Coefficient of friction and wear rate.

\begin{tabular}{lcc}
\hline Rotation & $\begin{array}{c}\text { Coefficient of } \\
\text { friction }\end{array}$ & $\begin{array}{c}\text { Wear rate } \\
\left(\mathbf{m m}^{3} \boldsymbol{N}^{-1} \boldsymbol{m}^{-1}\right)\end{array}$ \\
\hline 1 - fold & 0.71 & $16.1 \times 10^{-6}$ \\
2 - fold & 0.77 & $13.6 \times 10^{-6}$ \\
3 - fold & 0.86 & $14.9 \times 10^{-6}$ \\
\hline
\end{tabular}

2D profiles of wear tracks, presented in the right portion of Fig. 4, were used to calculate wear rate. Five or more profiles of each wear tracks were used to obtain average wear rate. Table 3 shows that wear is lower for coatings prepared with higher number of rotations, however it is not the lowest for the 3 -fold coating. On the other side, there is a direct relationship between friction coefficient and number of rotations.

In order to better understand wear behavior, wear tracks were analyzed by confocal optical microscopy. Pronounced wear scars may be observed inside the wear track of 1-fold coating, while smooth wear tracks were generated in 2-fold and 3-fold coatings (see optical micrographs and 2D profiles). Wear tracks of all three coatings are relatively clean, wear debris are not seen inside the wear tracks and are mostly agglomerated at the edges and ends of wear tracks. The highest amount of wear debris was observed for 1-fold coating.

Chemical composition of wear tracks and wear debris was investigated by EDS analysis. Fig. 5 shows that the main component of wear debris is oxygen which was not found neither inside, nor around the wear tracks. Considering that the ratio of oxygen and aluminum inside wear debris does not correspond to stoichiometric $\mathrm{Al}_{2} \mathrm{O}_{3}$, it might be assumed that a part of wear debris are oxides generated during wear tests. When TiAlN is in contact with alumina, $\mathrm{TiO}_{2}$ and $\mathrm{Al}_{2} \mathrm{O}_{3}$ oxides might form due to heating induced by friction [12], [13]. High coating hardness and presence of hard oxides inside wear tracks are main factors leading to a high friction coefficient in the present study.

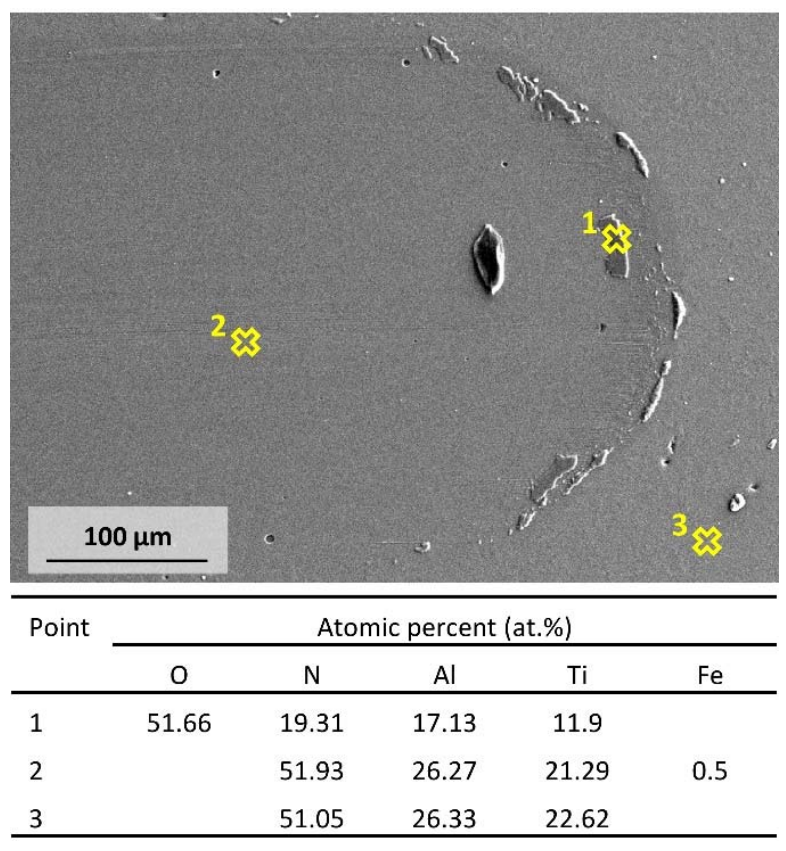

Fig. 3 Results of EDS analysis with scanning image microscopy (SEM) micrograph showing locations at which analysis was conducted. 
Generally, lower the roughness, lower the friction coefficient. However, although 3-fold coating was of the lowest roughness, the highest friction coefficient was measured for this coating. This may be attributed to its high hardness, i.e. high shear strength in contact with alumina ball.

Analysis of wear tracks reveals that all three coatings were worn by abrasion and tribochemical wear. If only abrasion and mechanical properties were considered, it would be expected that the wear loss has decreasing trend with the increase in the number of rotations. However, such a trend was not recorded in this study, which shows the complexity of tribological behavior, where wear loss is a result of interplay between mechanical and chemical mechanisms.

\section{CONCLUSIONS}

The presented study shows that the type of rotation used during coating processing inside industrial deposition units has great influence on coating properties. Surface roughness and mechanical properties are improved when switching from one to higher number of rotations. The differences between coatings prepared with one and two rotations are more pronounced than differences between coatings prepared by two and three rotations. Tribological properties are well related to surface topography and mechanical properties of coatings. However, the lowest wear rate was not obtained for the smoothest and the hardest coating, showing the complexity of tribological behavior. It may be concluded that tools requiring different types of rotations should not be placed in the deposition chamber in the same batch. In order to achieve same properties for coatings prepared with different rotations, deposition parameters should be carefully adjusted for each rotation type.

\section{ACKNOMEDGEMENTS}

This research was supported by the Serbian Ministry of Science and Technological Development and by the Slovenian Research Agency (ARRS) which the authors gratefully acknowledge.

\section{REEERENCES}

[1] Vennemann A., Stock H.R., Kohlscheen J., Rambadt S., Erkens G. (2003). Oxidation resistance of titanium-aluminium-silicon nitride coatings, Surface and Coatings Technology, pp.174-175, 408-415, DOI:10.1016/S0257-8972(03)00407-9.

[2] Horling A., Hultman A., Oden M., Sjolen J., Karlsson L. (2005). Mechanical properties and machining performance of TiAlN-coated cutting tools, Surface and Coatings Technology, 191, pp.384-392, DOI:10.1016/j.surfcoat.2004.04.056.
[3] Chen L., Paulitsch J., Du Y., Mayrhofer P.H. (2012). Thermal stability and oxidation resistance of Ti-Al-N coatings, Surface and Coatings Technology, 206, pp.2954-2960, DOI:10.1016/j.surfcoat.2011.12.028.

[4] Lin J., Mishra B., Moore J.J., Sproul W.D. (2006). Microstructure, mechanical and tribological properties of $\mathrm{Cr}_{1-\mathrm{x}} \mathrm{Al}_{\mathrm{x}} \mathrm{N}$ films deposited by pulsedclosed field unbalanced magnetron sputtering (PCFUBMS), Surface and Coatings Technology, 201, 4329-4334, DOI:10.1016/j.surfcoat.2006.08.090.

[5] Barshilia H.C., Selvakumar N., Deepthi B., Rajam K.S. (2006). A comparative study of reactive direct current magnetron sputtered CrAlN and $\mathrm{CrN}$ coatings, Surface and Coatings Technology, 201, pp.2193-2201. DOI:10.1016/j.surfcoat.2006.03.037.

[6] Lin J., Mishra, B., Moore J.J., Sproul W.D. (2008). A study of the oxidation behavior of $\mathrm{CrN}$ and $\mathrm{CrAlN}$ thin films in air using DSC and TGA analyses, Surface and Coatings Technology, 202, pp.32723283, DOI:10.1016/j.surfcoat.2007.11.037.

[7] Panjan P., Zalar A., Peterman T. (2008). Sputtering simulation of multilayer coatings in industrial PVD system with three-fold rotation, Journal of Vacuum Science and Technology, 82, pp.158-161, DOI:10.1016/j.vacuum.2007.07.053.

[8] Panjan M. (2013). Influence of substrate rotation and target arrangement on the periodicity and uniformity of layered coatings, Surface and Coatings Technology, 235, pp.32-44, DOI:10.1016/j.surfcoat.2013.06.126.

[9] Panjan M., Čekada M., Panjan P., Peterman T. (2007). Computer Simulation of Multilayer Structure of TiAlN/CrN Coatings, Plasma Processes and Polymers, 4, S921-S926, DOI:10.1002/ppap.200732206.

[10]Qi Z.B., Sun P., Zhu F.P., Wu Z.T., Liu B., Wang Z.C., Peng D.L., Wu C.H. (2013). Relationship between tribological properties and oxidation behavior of $\mathrm{Ti}_{0.34} \mathrm{Al}_{0.66} \mathrm{~N}$ coatings at elevated temperature up to $900^{\circ} \mathrm{C}$, Surface and Coatings Technology, 231, pp.267-272, DOI:10.1016/j.surfcoat.2012.02.017.

[11]Cheng Y.H., Browne T., Heckerman B., Meletis E.I. (2010). Mechanical and tribological properties of nanocomposite TiSiN coatings, Surface and Coatings Technology, 204, pp.2123-2129, DOI:10.1016/j.surfcoat.2009.11.034.

[12] Fateh N., Fontalvo G. A., Gassner G., Mitterer C. (2007). Influence of high-temperature oxide formation on the tribological behaviour of $\mathrm{TiN}$ and VN coatings, Wear, 262, pp.1152-1158, DOI:10.1016/j.wear.2006.11.006.

[13]Fox-Rabinovich G.S., Yamomoto K., Veldhuis S.C., Kovalev A. I., Dosbaeva G.K. (2005). Tribological adaptability of TiAlCrN PVD coatings under high performance dry machining conditions, Surface and Coatings Technology, 200, pp.1804-1813, DOI:10.1016/j.surfcoat.2005.08.057. 